Doi: 10.5212/PublicatioCi.Soc.v.21i1.0009

\title{
EMPODERAMENTO: POSSIBILIDADES DA PRÁTICA PROFISSIONAL INTERDISCIPLINAR NOS CENTROS DE REFERÊNCIA DE ASSISTÊNCIA SOCIAL EM PONTA GROSSA-PR
}

\author{
EMPOWERMENT: POSSIBILITIES FOR INTERDISCIPLINARY \\ PROFESSIONAL PRACTICE IN THE SOCIAL ASSISTANCE \\ REFERENCE CENTERS IN PONTA GROSSA-PR
}

\author{
Cristiane Gonçalves de Souza ${ }^{1}$ \\ Dirceia Moreira ${ }^{2}$ \\ Jussara Ayres Bourguignon ${ }^{3}$
}

\begin{abstract}
RESUMO
O presente trabalho objetiva refletir sobre os limites e as possibilidades da prática profissional da equipe interdisciplinar dos Centros de Referência de Assistência Social - CRAS e contribuir para o favorecimento do processo de empoderamento das famílias atendidas nessa instituição. Trata-se de pesquisa qualitativa, cujo contexto empírico foram os CRAS situados no Município de Ponta Grossa-PR. A pesquisa, realizada entre os anos de 2009-2010, desenvolveu-se por meio dos seguintes procedimentos metodológicos: revisão bibliográfica, estudo documental, observação, entrevista semi-estruturada com seis profissionais de Serviço Social, dois de Psicologia e dois de Pedagogia, e análise de depoimentos, tendo como referência as categorias centrais da pesquisa, as quais são: empoderamento, família, assistência social, prática profissional e equipe interdisciplinar.
\end{abstract}

Palavras-chave: Assistência social. Empoderamento. Protagonismo. Prática profissional. Equipe interdisciplinar.

\begin{abstract}
This paper aims to reflect on the limits and possibilities for the professional practice of interdisciplinary teams at the Reference Centers for Social Assistance - CRAS (in the Portuguese acronym) and contribute to facilitating the process of empowerment of the families attended by these institutions. It is a qualitative research whose empirical context involved the CRAS located in the city of Ponta Grossa-PR. A survey conducted between the years 2009-2010 was developed using the following instruments: literature review, documentary study, observation, semi-structured interviews with 06 professional social workers, 02 psychologists and 02 professionals concerned with pedagogical aspects. The study also included an analysis of testimonies related to the central categories of research, which are:
\end{abstract}

\footnotetext{
${ }^{1}$ Doutoranda no Programa de Pós-graduação em Ciências Sociais Aplicadas pela Universidade Estadual de Ponta Grossa.Mestre em Ciências Sociais Aplicadas UEPG. Graduada em Serviço Social UEPG. Email: souzacgj@gmail.com

${ }^{2}$ Professora Orientadora da Dissertação de mestrado. Doutora em Direito pela Pontifícia Universidade Católica de São Paulo (2004). Docente da Universidade Estadual de Ponta Grossa. E-mail: dirceia@dirceiam.com.br

${ }^{3}$ Professora Co-orientadora da Dissertação de mestrado Doutora em Serviço Social pela Pontifícia Universidade Católica de São Paulo. Docente da Universidade Estadual de Ponta Grossa. E-mail: jubourg@yahoo.com.br
} 
empowerment, family, social assistance, professional practice and interdisciplinary team.

Keywords: Social assistance. Empowerment. Protagonism. Professional practice and interdisciplinary team.

\section{Introdução}

Esta pesquisa, apresentada na dissertação de mestrado defendida com o título "Empoderamento: possibilidades da prática profissional nos Centros de Referência de Assistência Social - CRAS em Ponta Grossa-PR", ao Programa de Pós Graduação em Ciências Sociais Aplicadas da Universidade Estadual de Ponta Grossa-PR, teve como objetivo refletir a respeito dos limites e das possibilidades da prática profissional da equipe interdisciplinar dos CRAS contribuir para o favorecimento do processo de empoderamento das famílias atendidas nesta instituição.

Tal reflexão teve como parâmetro o processo de protagonismo e empoderamento, uma vez que, de acordo com a Política Nacional de Assistência Social de 2004, o CRAS é um lugar privilegiado para que haja ocorrência do fortalecimento das famílias e estímulo e incentivo do protagonismo delas. Dessa forma, buscamos identificar, no contexto da trajetória da Política Nacional de Assistência Social, como se efetivou o processo de constituição do protagonismo do usuário dos serviços socioassistenciais.

Outro aspecto que analisamos diz respeito à família, pois a Política Nacional de Assistência Social - 2004 tem como um dos eixos estruturantes de suas ações a Matricialidade Sociofamiliar, ou seja, a família é considerada espaço privilegiado de proteção social, socialização dos sujeitos e, dessa forma, é considerada alvo das ações socioassistenciais.

Em nosso entendimento, um trabalho que tenha como finalidade potencializar as capacidades das famílias é um trabalho que se relaciona a um processo de empoderamento, no sentido de que elas possam se perceber como sujeitos que têm capacidades de serem protagonistas de sua própria história de vida.

Sobre a prática profissional, tencionamos levantar elementos para a realização de uma leitura crítica dela, elementos esses que nos fornecessem subsídios para uma análise a respeito da possibilida- de de aprática profissional da equipe interdisciplinar do CRAS contribuir para empoderamento e afirmação do protagonismo das famílias usuárias.

\section{Metodologia da pesquisa}

Inicialmente, importa destacar que se trata de pesquisa qualitativa, pois trabalhamos com base em dados que não podem ser mensuráveis, visto que se refere a um tipo de pesquisa que buscou explorar os significados de determinado fenômeno aos sujeitos pesquisados (MINAYO, 1998).

Para conhecer a realidade pesquisada, utilizamos alguns instrumentais, entre eles, destacamos: a pesquisa bibliográfica, o estudo documental, a entrevista semiestruturada, coleta e análise de depoimentos.

Empregamos a pesquisa bibliográfica como procedimento metodológico, pois ela permite amplo alcance de informações e admite o emprego de dados dispersos em inúmeras publicações, dessa forma, contribui para a melhor definição dos conceitos que envolvem o objeto de estudo proposto. (GIL, 1994)

Realizamos o estudo de documentos, como as atas do Conselho Municipal de Assistência Social de Ponta Grossa. Por meio desses documentos, tivemos acesso às informações referentes à implantação do SUAS no município e, consequentemente, às informações sobre a implantação dos CRAS. Também acessamos os históricos que trazem informações sobre todo o processo de constituição dos CRAS a partir de seus territórios locais, os quais se encontram nas próprias unidades. Tais documentos forneceram informações que nos ajudaram a caracterizar os CRAS dentro da realidade local, sua implementação, formação e área de abrangência.

A Política Municipal de Assistência Social foi o pano de fundo de nossa pesquisa e o contexto empírico dela foram os Centros de Referência de Assistência Social - CRAS, situados em Ponta Grossa-PR, onde os sujeitos entrevistados desenvolviam sua prática profissional. 
De acordo com princípios e diretrizes do Sistema Único de Assistência Social - SUAS, a equipe básica de profissional atuante no CRAS é composta por uma equipe interdisciplinar: Assistente Social, Psicólogo e Pedagogo.

Assim sendo, os sujeitos de nossa pesquisa foram os profissionais que atuam na equipe básica interdisciplinar dos CRAS: Assistente Social, Psicólogo e Pedagogo, os quais participaram de uma entrevista semi-estruturada ${ }^{4}$ com um roteiro de perguntas flexíveis, onde tiveram a possibilidade de discorrer sobre o tema proposto de acordo com experiências e conhecimentos em torno do tema desta pesquisa.

Para Moroz e Gianfaldoni (2002, p. 66), a entrevista tem a vantagem de envolver uma relação pessoal entre pesquisador/sujeito, o que facilita maior esclarecimento de pontos nebulosos. Sendo assim, escolhemos utilizar o instrumental entrevista semi-estruturada para coleta de dados junto aos nossos sujeitos de pesquisa, a fim de ter maior interação com eles. Trabalhamos com algumas questões que abordassem as categorias centrais desta pesquisa, as quais são: empoderamento, família, assistência social, prática profissional e equipe interdisciplinar.

Referente à entrevista semi-estruturada, ela foi composta por oito questões, as quais tinham como tema central o processo de empoderamento das famílias atendidas no CRAS e a prática profissional da equipe interdisciplinar do CRAS.

O número total de participantes de nossa pesquisa foram 10: seis assistentes sociais, duas psicólogas e duas pedagogas.

Destacamos que conhecer a experiência dos profissionais que participaram de nossa pesquisa e que atuam no cotidiano dos CRAS foi de suma importância, pois, à medida que se realizava essa aproximação com a realidade deles, tal aproximação não apenas fortaleceu as discussões da presente pesquisa, mas também a qualificou no sentido de que esse contato possibilitou que novos questionamentos fossem sendo incorporados à pesquisa, ao passo que novas reflexões foram sendo construídas com base na nossa aproximação com a realidade dos sujeitos pesquisados.

\footnotetext{
${ }^{4}$ As entrevistas foram realizadas no final do ano de 2009 e início de 2010.
}

\section{Resultados e discussão}

Esta pesquisa, apresentada na dissertação de mestrado, já nominada anteriormente, foi composta por quatro capítulos, em que, no primeiro capítulo, apresentamos a trajetória da Assistência Social no Brasil a partir da década de 1930. Adotamos esse período como marco temporal, pois a partir dessa data ocorreram as primeiras ações estatais na área socioassistencial. Ressaltamos que, na construção de tal trajetória, tentamos identificar o processo de constituição do protagonismo do usuário da Assistência Social, visto que considerar o usuário como sendo um sujeito portador de direitos é um processo recente.

Neste capítulo, evidenciamos que a pobreza era considerada como uma disfunção pessoal. Com o passar dos anos, observamos que essa ideia foi sendo contestada: será que a pobreza está restrita única e exclusivamente a um problema de ordem individual? Pudemos perceber que não, que a pobreza não se trata apenas de uma questão individual, mas é permeada por questões objetivas e subjetivas, ou seja, o modo de produção de uma sociedade influencia e, por conseguinte, é importante analisar as condições objetivas de vida do usuário, por isso as condições de vida da população não podem ser entendidas fora da história (MARX, 2002), pois devem ser consideradas nessa análise para não se correr o risco de realizar um julgamento pautado apenas nas impressões que estão na aparência.

A esse respeito, Yazbek (1996, p. 23) sinaliza que:

É importante ainda considerar que a pobreza não é apenas uma categoria econômica, não se expressa apenas pela carência de bens materiais. Pobreza é também uma categoria política que se traduz pela "carência de direitos, de possibilidades e de esperança". Esta face da pobreza suscita novos desafios à gestão estatal dos processos de inclusão/exclusão social dos subalternos e, particularmente, à assistência social, historicamente campo dos excluídos.

Referente à questão da pobreza não ser apenas uma categoria econômica, mas também política, Demo (1988, p. 08) expõe que "a pobreza política é uma tragédia histórica, na mesma dimensão que da pobreza socioeconômica, e retrata-se, entre outras coisas, na dificuldade de formação de um povo 
capaz de gerir seu próprio destino e na dificuldade de institucionalização da democracia".

Aliada à pobreza econômica, a pobreza política produz sujeitos apáticos que sequer se percebem como destinatários de direitos e também de esperança de uma vida melhor, de acordo com Souza (2010, p. 01):

A resignação e o medo da participação são resultados da cultura autoritária, que perpassa nossa história e instalou-se na nossa cultura e, portanto, nos nossos próprios hábitos. Participar, em vez de ser regra geral, tornou-se uma exceção. Temos, então, o cidadão limitado, fechado, sem iniciativa, dependente.

Dessa forma, "superar a assistência social enquanto ajuda significa conferir-lhe o estatuto de política social. Como forma discriminada de atenção, é necessário que essa área ganhe nova visibilidade, saia do limbo". (SPOSATI et. al., 1999 , p. 27)

Para a assistência passar da perspectiva de assistencialismo, é necessário um trabalho no qual essa área ganhe visibilidade, em que sejam suscitadas discussões referentes às desigualdades sociais existentes em nosso país e as correlações de forças que são inerentes a esse processo. Não é possível a construção de uma sociedade mais justa e com equidade se essas considerações não forem realizadas, pois uma "sociedade com tal desenho é obra coletiva para a coletividade" (CAMPOS, 2009, p. 21), e que necessita da mobilização de diversos atores compromissados ética e politicamente com esse projeto societário.

Sob esse aspecto, Pereira (2000, p. 186) expõe que, referente à assistência, "área malcompreendida no Brasil", é importante que as análises referentes a essa área sejam conduzidas considerando o seu percurso que é complexo e que ao mesmo tempo é um processo que possui "caráter racional, ético e cívico".

É racional, pois deve ser fruto "de um conjunto articulado de decisões coletivas que, por sua vez, devem se basear em indicadores científicos" (PEREIRA, 2000, p. 186). Isso pressupõe que para maior efetividade na área da assistência, necessário se faz que ela seja subsidiada por pesquisas, bem como sejam realizados diagnósticos e constantes avaliações das ações desenvolvidas nessa área com ênfase para o impacto delas (PEREIRA, 2000).
Por sua vez, é ético, visto que o enfrentamento das injustiças sociais diz respeito a uma responsabilidade moral da sociedade "mais do que um ato de eficácia administrativa [...]. Contra o egoísmo imoral de se tirar proveito da fome, da miséria, da ignorância, da falta de perspectivas de milhares de pessoas, deve prevalecer o sentimento de que é moralmente condenável não se fazer de tudo para sanar essas calamidades sociais" (PEREIRA, 2000, p.187).

É finalmente um processo que exige caráter cívico, uma vez que a materialização dos direitos de cidadania social deve ser o alvo das ações de uma política de assistência social, na qual "concretizar direitos sociais significa prestar à população, como dever do Estado, um conjunto de benefícios e serviços que lhe é devido, em resposta às suas necessidades sociais". (PEREIRA, 2000, p.187). O caráter cívico da assistência se concretiza no momento em que essa área deixa de ser tratada apenas como ação pontual e passa a se constituir como política social a qual deve ser conduzida pelo Estado e, nessa condução, o Estado tem o papel de ser o efetivador do acesso à assistência à população que dela necessita, e esse acesso deve ocorrer a partir da premissa do direito.

Dando continuidade, o segundo capítulo inicia com a contextualização da década de 1990, com destaque para a implementação da Lei Orgânica de Assistência Social - LOAS de 1993, momento importantíssimo para essa área, pois a partir de então ela ganhou status de política social pública.

Ainda neste capítulo, enfatizamos a reforma neoliberal que ocorre no Brasil. Situar esse contexto tornou-se pertinente em nossa pesquisa, tendo em vista que não apenas as políticas sociais sofrem impactos da onda neoliberal, mas, sobretudo o mundo do trabalho a partir de então ganhou novas características que incidem nas relações trabalhistas do setor privado e do setor público.

Prosseguindo com a trajetória da assistência, chegamos ainda ao segundo capítulo, ao momento de formulação da atual Política Nacional de Assistência Social e o Sistema Único de Assistência Social - SUAS, momento esse que gera mudanças em toda a gestão das ações socioassistenciais no território nacional.

A Política Nacional de Assistência Social PNAS em vigência indica que a realização das ações deve ocorrer de forma integrada e articulada 
às demais políticas setoriais. Para tanto, é necessário levar em conta as desigualdades existentes em cada território, com intuito de buscar o enfrentamento delas de forma que não haja uma generalização das situações de vulnerabilidade social, mas cada caso precisa ser considerado com fundamento em sua particularidade, para que sejam garantidas as necessidades sociais básicas da população (BRASIL, 2004).

A PNAS 2004 institui que os serviços prestados na área da Assistência Social serão classificados por: Proteção Social Básica e Proteção Social Especial.

$\mathrm{Na}$ Proteção Social Básica, estão inscritos os trabalhos relacionados à prevenção, ou seja, o objetivo é atuar em situações familiares ou até mesmo individuais, em que há situações de vulnerabilidade social como consequência da pobreza e onde ocorra a fragilização dos vínculos afetivos, os quais ainda não se romperam (BRASIL, 2004).

O local designado para prestar atendimento às demandas dos serviços de Proteção Social Básica é o Centro de Referência de Assistência Social - CRAS, o qual se constitui em uma unidade pública estatal de base territorial, cujo objetivo é trabalhar com famílias e indivíduos inseridos em seu contexto comunitário, efetivando os direitos sociais deles, sobretudo daqueles que se encontram em situação de vulnerabilidade social (BRASIL, 2004).

A Proteção Social Especial, por sua vez, é subdividida em média e alta complexidades, em que, de acordo com a PNAS (2004, p. 34), "as linhas de atuação com as famílias em situação de risco devem abranger desde o provimento de seu acesso a serviços de apoio e sobrevivência até sua inclusão em redes sociais de atendimento e de solidariedade".

O lócus privilegiado de atendimento das demandas dos serviços especializados é o Centro de Referência Especializado de Assistência Social CREAS. Trata-se de uma unidade pública estatal.

O Sistema Único de Assistência Social SUAS, que é preconizado na PNAS 2004, implementa um regime geral para a gestão da Assistência Social no Brasil, materializa o conteúdo da Lei Orgânica de Assistência Social - LOAS e define e organiza os elementos essenciais e imprescindíveis à execução da política de assistência social (BRASIL, 2004).
Os eixos que estruturam a gestão do SUAS são: Matricialidade Sociofamiliar, Descentralização político-administrativa e Territorialização, fortalecimento da relação entre Estado e Sociedade Civil, Financiamento, Controle Social, participação popular/cidadão usuário, Política de Recursos $\mathrm{Hu}-$ manos e Informação, o Monitoramento e a Avaliação (BRASIL, 2004).

Não era foco deste trabalho discorrer a respeito de todos os eixos estruturantes do SUAS, nesse sentido, detemo-nos apenas na Matricialidade Sociofamiliar, sob esse aspecto, a PNAS (2004, p. 40) indica que "A centralidade da família é garantida à medida que, na Assistência Social, com base em indicadores das necessidades familiares, se desenvolva uma política de cunho universalista, [...] que suportem as tarefas cotidianas de cuidado e que valorizem a convivência familiar e comunitária”.

Ao trabalhar com famílias, pode-se afirmar que as ações ora podem ser direcionadas com um tom de privilegiar esse espaço como sendo profícuo para alcance dos sujeitos e ora pode-se culpabilizar a instituição familiar pela situação de vulnerabilidade em que ela se encontra. Nesse sentido, ao considerar-se a família como foco de atenção das políticas sociais, as ações desenvolvidas não devem partir de um viés disciplinador e moralizador dela, mas deve-se partir da premissa do fortalecimento, respeitando sua individualidade, suas tradições e cultura independentemente de sua situação.

$\mathrm{Na}$ sequência deste capítulo, realizamos uma caracterização do Munícipio de Ponta Grossa, locus de nossa pesquisa, bem como apresentamos o momento de reorganização das ações assistenciais locais a partir do ano de 2005, com destaque para os CRAS, visto que são nos CRAS que os sujeitos de nossa pesquisa desenvolviam sua prática profissional.

Após contextualizarmos a trajetória da Assistência Social no Brasil, chegamos ao terceiro capítulo, o qual versa sobre as possibilidades e as características do processo de empoderamento, ocasião em que trazemos as contribuições de alguns autores, estudiosos do termo, ressaltando a perspectiva freireana, a qual aponta para a importância de desenvolvimento do processo de empoderamento numa perspectiva dialógica. 
Freire deu uma perspectiva transformadora ao termo empoderamento, usou o termo no original inglês empowerment, cujo significado é: “A) dar poder a; B) ativar as potencialidades criativas; C) desenvolver a potencialidade criativa do sujeito; D) dinamizar as potencialidades do sujeito" (FREIRE; SHOR 1986, p. 10).

Freire, em diálogo com Shor (1986), explicita que o empoderamento é resultado de um processo político, dessa forma, busca romper apenas com a dimensão individual e psicológica, pois, para o autor, o empoderamento não é individual, nem comunitário, nem social, mas relaciona-se à classe social. $\mathrm{O}$ autor considera a perspectiva individual, pois afirma que não pretende reduzir tudo a uma questão de classes, mas assevera que quando esse processo ocorre deve permear as relações sociais nas quais o indivíduo está inserido, por isso defende o empoderamento a partir da dimensão de classe social.

Freire não desconsidera que o empoderamento pode ocorrer individualmente, no entanto enfatiza que, ao se pretender empoderar um sujeito, a sua luta deve ser coletiva, com vistas à libertação da classe trabalhadora, a qual é dominada pelos ideais ditados pelo modo de produção capitalista.

Quando o empoderamento é considerado apenas como um processo que deve se efetivar individualmente, corre-se o risco de fragmentar as demandas das classes subalternas, demandas que são coletivas, pois são consequência do modo de produção capitalista. Dessa forma, não se pode substituir interesses que são universais às classes subalternas por interesses individuais e específicos, tal situação tende a desqualificar a luta dos segmentos mais espoliados pelo capitalismo, ou seja, a classe trabalhadora (SIMIONATO, 2009).

Freire parte da hipótese de que ao falar de empoderamento não se pode isolar o sujeito de todos os outros eventos que o cercam socialmente, como no caso da classe trabalhadora, a qual se encontra em posição de dominação frente ao sistema capitalista.

Empoderar o ser humano é um processo político que deve atingir as classes sociais que são oprimidas por sua situação de pobreza, a qual não se restringe apenas a uma questão econômica, mas que também se relaciona a uma pobreza política. Nesse processo de empoderar, as classes subalternas, a cultura, os valores, a história delas não deve ser des- considerada, pois todo o ser humano, por mais alienado que seja, possui capacidade criadora (FREIRE, 1980).

Trata-se de um processo no qual os sujeitos não serão receptores passivos, porém, por meio da participação dialógica eles se tornam construtores desse novo conhecimento, em que "em vez de se transferir o conhecimento estaticamente, como se fosse uma posse fixa [...] o diálogo requer uma aproximação dinâmica na direção do objeto" (FREIRE; SHOR, 1986, p. 124).

"Empowerment deve ser o meio de possibilitar que os alunos "examinem e, seletivamente, apropriem-se daqueles aspectos da cultura dominante que lhes oferecerão a base para definir e transformar a ordem social, mais ampla, em vez de simplesmente servir a ela" (FREIRE e MACEDO, 2006, p.100).

Avançando nessa discussão, o empoderamento pode contribuir para o desenvolvimento de um processo de criticidade, no qual o homem terá possibilidade de chegar a ser sujeito por meio de uma reflexão sobre sua situação, sobre seu ambiente concreto (FREIRE, 1980).

Na sequência do capítulo, fomos instigados a trazer à tona a discussão referente ao termo protagonismo, visto que no desenvolvimento do processo de empoderamento o protagonismo surge como um elemento central no depoimento dos sujeitos entrevistados. O mesmo ocorre com a categoria ações socioeducativas, a qual é mencionada tanto na fala dos sujeitos como também emerge das discussões teóricas que realizamos com Paulo Freire, o qual aponta que as ações socioeducativas podem configurar-se como estratégias para a criação de um meio favorável ao empoderamento.

No que tange ao protagonismo, percebemos que para que ocorra a ampliação do protagonismo dos usuários da assistência, as ações desenvolvidas não podem ter como pressuposto o assistencialismo, entendido aqui como mera incorporação do ser humano em um processo como se ele fosse objeto e não sujeito (FREIRE, 1981).

Assistencialista, no sentido de deixar os usuários tutelados ao serviço e não na perspectiva de que eles possam participar efetivamente, no caso dos CRAS, participar das ações desenvolvidas nessa instituição e visualizar suas potencialidades e capacidade de enfrentamento de suas problemáticas. 
Na perspectiva Freireana, tal participação não pode se efetivar como ocorre na educação bancária, mas sim tendo como ponto de partida a educação libertadora.

Por educação bancária, entende-se o ato de depositar um conhecimento pronto e acabado nos educandos, em que estes serão receptores de algo. No entanto, mesmo na educação bancária. espera-se que os educandos exercitem a reflexão, contudo o processo reflexivo ocorre a partir daquilo que está sendo posto, a educação bancária não exclui a reflexão, ela controla o âmbito da reflexão, pois quer comprovar e validar o que está sendo afirmado como verdade/ ciência.

O sujeito não é sujeito, mas objeto do educador, apenas recebendo passivamente determinado conhecimento sem a possibilidade de questionamento e de indagação. Em diálogo com Shor, Freire (1986, p. 124) explicita que esse tipo de educação não faz parte de uma ação dialógica tendo em vista que "em vez de se transferir o conhecimento estaticamente, como se fosse uma posse fixa [...], o diálogo requer uma aproximação dinâmica na direção do objeto".

O diálogo promove uma relação mais dinâmica entre educador-educando, em que os educandos também têm condições de serem educadores a partir do momento em que mediante os processos de reflexão coletiva compartilham suas experiências e apontam que também são detentores de conhecimento, o diálogo configura-se como instrumento de empoderamento. Esse processo de reflexão, se adotado a partir de uma visão transformadora e de libertação do oprimido, relaciona-se com "a práxis [...] é reflexão e ação dos homens sobre o mundo para transformá-lo, sem ela, é impossível a superação da contradição opressor-oprimidos" (FREIRE, 2005, p. 21).

$\mathrm{Na}$ maioria dos casos, como em palestras, encontros socioeducativos e grupos de convivência, em que se pretende desenvolver um trabalho que tenha como foco o protagonismo dos sujeitos, ainda é utilizada a Educação formal, a qual vincula-se à proibição ao pensar verdadeiro (FREIRE, 2005).

Para Mészaros (2005), isso ocorre devido ao fato de que estamos inseridos dentro do contexto capitalista. Nesse caso, as atividades educativas se manifestam dentro de um limite, que é imposto pelo próprio capital, por isso ocorre a proibição do pensar verdadeiro.
Em processos socioeducativos, a presença do diálogo se faz primordial, pois o sujeito a quem se pretende "educar" está inserido em determinada realidade, portanto, tal processo educador tem que considerar essa realidade, caso contrário será mera transmissão de um conhecimento dos que se julgam sábios àqueles que não são sábios. "Tal ideia é fundamentada na opressão e atribuição da ignorância sempre ao outro, percebemos que tal concepção de educação se edifica sobre princípios frontalmente opostos à idéia de protagonismo [...]" (RYZEWSKI; STORTI 2010, p. 05).

Mészaros (2005, p. 12) menciona que o capitalismo impõe uma educação com finalidade de dominar o ser humano, por sua vez o papel da educação que liberta seria o de "transformar o trabalhador em um agente político que pensa, que age, e que usa a palavra como arma para transformar o mundo".

Para esse autor, a "educação para além do capital deve, portanto, andar de mãos dadas com a luta por uma transformação radical do atual modelo econômico e político hegemônico" (MÉSZAROS, 2005, p. 12).

A diferença entre a educação que aliena e a educação libertadora encontra-se no fato de que esta, em vez de depositar um conhecimento fixo e estático, proporciona aos homens a reflexão a respeito da sua própria inserção no mundo. Por meio da práxis, esse homem se comunica com o mundo no qual está inserido, em vez de ser um receptor passivo dessa relação com o mundo, torna-se um agente ativo, que age e transforma o mundo que lhe cerca.

No quarto capítulo, realizamos uma reflexão em torno da prática profissional e dos limites e das possibilidades de ela mesma contribuir para o desenvolvimento do processo de empoderamento. Intentamos, ainda, analisar os desafios da prática profissional da equipe dos CRAS tendo a interdisciplinaridade como eixo de análise, visto que nos depoimentos dos sujeitos eles relatam a dificuldade de, no cotidiano profissional, trabalhar tendo a interdisciplinaridade como ponto de partida de suas ações.

Outro ponto analisado neste capítulo foram as condições de trabalho oferecidas à equipe profissional do CRAS, tendo em vista que os sujeitos entrevistados em várias ocasiões apontam a estrutura de trabalho como aspecto que limitava sua intervenção junto às demandas familiares. 
Neste capítulo, reconhecemos as possibilidades de a prática profissional da equipe interdisciplinar do CRAS contribuir para o desenvolvimento do processo de empoderamento.

As ações desenvolvidas pela equipe, quando organizadas pela lógica do trabalho interdisciplinar e bem articuladas com as diversas áreas que compõem a equipe, " têm possibilidades de alterar o que está posto” (CFP/CFESS, 2007, p. 22).

A prática profissional da equipe interdisciplinar tem possibilidades de atuar de forma que seja desmistificada a ideia de naturalização da pobreza e por meio da soma do conhecimento e das diversas experiências compartilhadas pela equipe há a possibilidade de se pensar numa intervenção que vise atender às necessidades dos usuários atendidos no CRAS de forma mais ampla, visto que as diversas profissões inseridas nesse contexto têm condições de "Propor, a partir de suas intervenções, atravessar o cotidiano de desigualdades e violências dessas populações, visando ao enfrentamento e superação das vulnerabilidades, investindo na apropriação, por todos (as), do lugar de protagonista na conquista e afirmação de direitos" (CPF/CFESS, 2007, p. 23).

Os profissionais que compõem a equipe profissional de referência do CRAS têm condições de contribuir para o empoderamento das famílias atendidas nessa instituição, uma vez mesmos possuem conhecimento teórico metodológico que foram construídos tendo como base a luta e a afirmação da cidadania, a defesa dos direitos humanos e a promoção da vida (CPF/CFESS, 2007). Dessa forma, a atuação com as famílias exige da equipe profissional "uma atitude ante a formação e conhecimento, que se evidenciam no reconhecimento das competências, atribuições, habilidades, possibilidades e limites das disciplinas, dos sujeitos, do reconhecimento da necessidade de diálogo profissional e cooperação" (CPF/CFESS, 2007, p. 39 e 40).

Assistentes Sociais, Psicólogos e Pedagogos têm um papel estratégico a ser desempenhado junto às demandas familiares apresentadas nos CRAS, no entanto, reconhecemos que "as possibilidades de atuação profissional não podem ser desvinculadas das condições e processos em que se realiza o traba1ho" (CFP/CFESS, 2007, p. 43).

Além da necessidade de capacitar a equipe interdisciplinar do CRAS, não podemos ignorar que somente a capacitação desses profissionais não é suficiente como requisito de um trabalho interdisciplinar para empoderar as famílias, é importante, sobretudo oferecer a esses profissionais condições dignas de trabalho. Para tanto, três elementos precisam ser considerados: "as atividades exercidas pelos trabalhadores(as), as condições materiais, institucionais, físicas e financeiras, e os meios e instrumentos necessários ao seu exercício" (CFP/CFESS, 2007, p. 43).

Considerar tais elementos como sendo necessários para a qualidade de uma intervenção realizada a partir da interdisciplinaridade é fundamental, pois se assim não procedermos podemos cair na armadilha de culpabilizar o profissional pelas limitações encontra na execução de suas ações profissionais.

\section{Conclusão}

Diante dessas análises, percebemos que, ao abordarmos a respeito de as possibilidades da prática profissional da equipe interdisciplinar do CRAS contribuírem para o processo de empoderamento das famílias atendidas na instituição, ficou clara a amplitude da temática, tendo em vista que está inscrita no contexto de uma nova relação, qual seja, além da nova configuração da assistência social a partir do SUAS existe também uma nova relação instituída nas relações de trabalho, as quais muitas vezes conformam as práticas profissionais.

Ressaltamos que as reflexões realizadas e apresentadas neste trabalho, em relação à prática profissional da equipe interdisciplinar do CRAS e as possibilidades de desenvolvimento do processo de empoderamento, constituem-se em reflexões que não pretendem esgotar a temática proposta, pois nossa pretensão foi realizar uma primeira análise sobre o objeto de pesquisa proposto.

As considerações aqui realizadas pretendem configurarem-se como subsídios para novas reflexões que possam surgir a respeito da temática e ainda colaborar para que os profissionais atuantes na assistência social, principalmente os profissionais dos CRAS, possam, com base no referencial teórico construído nesta pesquisa, realizar reflexões que contribuam para perceberem além dos limites, as possibilidades que se colocam na intervenção junto às demandas familiares. 
Mediante as discussões teóricas que apresentamos e pelos depoimentos dos sujeitos entrevistados, sinalizamos para algumas questões que sugerem limites e possibilidades da prática profissional da equipe interdisciplinar contribuir para o processo de empoderamento das famílias atendidas nos CRAS.

Sobre as possibilidades, percebemos que, no tocante às famílias atendidas, a PNAS de 2004 aponta para uma nova visão acerca da abordagem nos trabalhos realizados com a família, qual seja, uma abordagem que considere a capacidade de, em meio a situações de vulnerabilidades e riscos sociais, visualizar forças e não apenas as fragilidades dessas famílias, mediante uma leitura macro e não microssocial.

Para favorecer essa abordagem, a PNAS de 2004 sinaliza para a realização de ações socioeducativas com tais famílias, nas quais o CRAS é um espaço privilegiado para tanto. Sobre as ações socioeducativas, as discussões teóricas realizadas revelaram-nos que elas, para se configurarem como ações que favoreçam o protagonismo e o empoderamento das famílias, não podem ser desenvolvidas com base na lógica bancária, ou seja, nas palavras de Mészaros (2005), em ações educativas não se pode ignorar dois elementos: o modo de produção capitalista e a relação de classe, aspecto que Freire também aponta como sendo fundamental para a ocorrência do empoderamento.

Quando mencionamos que a necessidade de considerar a lógica do capital, estamos sinalizando que as ações socioeducativas não podem se restringir à mera incorporação das famílias nas ações desenvolvidas, pois se assim ocorrer estaremos partindo da lógica capitalista.

De acordo com o resgate histórico que realizamos sobre a trajetória da Assistência Social Brasileira, percebemos que a população empobrecida, na condição de classe subalterna, foi apenas sendo incorporada às ações assistenciais, em que muitas vezes a classe dominante impunha sobre a população os seus interesses. A classe dominante afirmava que os seus projetos eram os mesmos das classes subalternas, quando na verdade tal fato ocorria apenas para produzir uma população passiva, que não contrariasse a ordem vigente.

Esse contexto gerou na população um sentimento de passividade, o que por sua vez traz, na atualidade, o desafio de, por intermédio das ações socioeducativas, estimular as famílias usuárias da assistência social a construírem seu próprio repertório, em que se percebam como protagonistas.

Ainda sobre as famílias usuárias do CRAS, percebemos que as possibilidades de se realizar um trabalho no viés do empoderamento são potencializadas se tal trabalho partir da premissa de considerar a família e os seus membros. Para tanto, deve-se ter cuidado de não fragmentar a família no desenvolvimento das ações, visto que a vulnerabilidade que incide sobre um membro da família atingirá não somente esse membro, mas toda a família.

Outro aspecto que ficou evidente é que nesse contexto de afirmação da centralidade da família nas ações socioassistenciais, necessário se faz desenvolver ações que não retrocedam em ações moralizantes que culpabilizam a família por não dar conta de seus problemas diários. Dessa forma, o trabalho com as famílias e seus membros deve privilegiar ações de acolhimento e escuta delas, sem incorrer em ações de ajustes delas.

Para fortalecer a função protetiva da família, ela precisa ser protegida por meio da realização de um trabalho social que seja capaz de produzir ações que não terão o viés disciplinador ou controlador e que desconsideram que muitas vezes as famílias enfrentam situações de vulnerabilidade e risco social como consequência da ausência de respostas públicas frente às suas demandas.

Ou seja, em alguns momentos de nossa pesquisa, apontamos que a questão da pobreza e da vulnerabilidade social não diz respeito apenas a questões de cunho objetivo/material, mas também relacionam-se com questões subjetivas.

Nesse sentido, as ações socioeducativas realizadas com as famílias atendidas no CRAS devem conjugar duas ações: de proteção social e de educação.

Nesse contexto, as ações de proteção social referem-se aos recursos materiais que são disponibilizados a essas famílias pelas políticas sociais, não somente a política de assistência, mas de saúde, educação, moradia, emprego, etc.

Por sua vez, as ações educativas dizem respeito aos recursos, que não são materiais, mas são tão importantes quanto. Tais recursos podem ser disponibilizados às famílias por meio do desenvolvimento 
de atividades que as levem a momentos de reflexão, em que possam se perceber como capazes de mudar sua trajetória de vida. Nesse processo, é importante o diálogo, a reflexão, a comunicação, a participação, a informação, enfim, um conjunto de ações que, se somadas, têm a possibilidade de facilitar o estímulo do protagonismo das famílias atendidas no CRAS e, consequentemente, favorecer o empoderamento.

No que tange às possibilidades da prática profissional, percebemos, pelas reflexões encontradas em Paulo Freire e Horochovski, que os profissionais configuram-se como catalisadores do processo de empoderamento, e isso não significa que darão poder às famílias atendidas nos CRAS, mas implica que podem favorecer a ocorrência do empoderamento por ações cuja finalidade seja ir além de um simples repasse de conhecimentos fixos e preestabelecidos, mas, ao contrário, implica estabelecer diálogo com tais famílias.

Para estabelecer esse diálogo, parte-se do pressuposto de que os profissionais precisam visualizar que essas famílias são sujeitos e não meros objetos passivos, dessa forma, percebe-se que, mediante tais ações, o CRAS pode se configurar como espaço de ampliação do protagonismo das famílias atendidas.

Mesmo que Assistentes Sociais, Psicólogos e Pedagogos detenham conhecimentos teóricos que se distinguem entre si, “[...] o diálogo entre essas categorias profissionais aliará reflexão crítica, participação política, compreensão dos aspectos objetivos e subjetivos inerentes ao convívio e à formação do indivíduo [...]". (CFP/CFESS, 2007, p. 41)

Ainda sobre as possibilidades de empoderamento, é necessário que a intervenção da equipe interdisciplinar do CRAS busque o enfrentamento de uma tendência que se faz presente atualmente no âmbito dessa instituição, qual seja, “[...] restringir a atuação aos atendimentos emergenciais a indivíduos, grupos ou famílias, o que pode caracterizar os CRAS e a atuação profissional como um "grande plantão de emergências", ou um serviço cartorial de registro e controle das famílias para acessos a benefícios de transferência de renda (CFP/CFESS, 2007, p. 31)

Nesse sentido, os profissionais que compõem a equipe interdisciplinar do CRAS possuem um papel fundamental, na medida em que o seu trabalho junto às famílias estimule o debate [...] "sobre o reconhecimento e defesa do papel da Assistência Social e das políticas sociais na garantia dos direitos e melhoria das condições de vida; isso sem superestimar suas possibilidades e potencialidades no enfrentamento das desigualdades sociais [...]" (CFP/CFESS, 2007, p. 40).

Nesse contexto, no entanto, não se pode ignorar certos pressupostos: estrutura de trabalho oferecida aos profissionais e o trabalho interdisciplinar.

Logo, para que os profissionais tenham condições de criarem um espaço que seja favorável ao desenvolvimento do processo de empoderamento necessário se faz oferecer a esses profissionais condições de trabalho adequadas.

No caso dos CRAS, do município de Ponta Grossa-PR, ficou evidente que os mesmos muitas vezes não contam com tais condições, o que implica certas limitações para o trabalho da equipe.

Além dos depoimentos evidenciarem a precariedade das condições de trabalho da equipe do CRAS, evidenciam, ainda, que uma vez inscrito na modalidade de Gestão Plena da Assistência Social, o município além de buscar desenvolver os serviços socioassistenciais com vistas ao atendimento pleno das demandas dos usuários desse serviço, está implícito que o município também deve buscar oferecer aos profissionais uma estrutura de trabalho adequada e condizente com suas necessidades profissionais.

Mas quando nos deparamos com esse aspecto da estrutura de trabalho, lembramos que as práticas profissionais são resultados do movimento da história, assim sendo, sofrem influências das conjunturas sociais (econômica, política, cultural, etc.).

Dessa forma, ao mencionarmos o desafio das condições de trabalho dos profissionais dos CRAS e a dificuldade de o gestor municipal em implementar melhores condições de trabalho aos profissionais, consequentemente, não podemos ignorar que, no tocante ao mundo do trabalho, a partir da década de 1990 as relações trabalhistas sofreram fortes impactos do ideário neoliberal, em que a lógica era flexibilizar as relações de trabalho, acarretando precarização delas.

Assim sendo, se por um lado o texto da PNAS de 2004 aponta para um novo momento para a Assistência Social e sinaliza um arcabouço de princípios e diretrizes que conformam as ações socioassistenciais numa perspectiva cidadã não só para os usuários, mas também aos trabalhadores da assistência social, 
por outro, o ideário neoliberal aponta para corte de recursos na área social. Esse enxugamento rebate sobre os salários dos profissionais que trabalham na implementação e execução das políticas sociais.

Os profissionais do CRAS vivem sobre o dilema da dicotomia entre: projeto profissional e estatuto assalariado, ou seja, reconhecem que sua intervenção tem condições de oferecer um trabalho que alcance resultados mais satisfatórios no que tange ao empoderamento das famílias. No entanto, reconhecem que muitas vezes as condições de trabalho configuram-se como entraves para o atendimento das demandas familiares apresentadas nos CRAS.

Ainda concernente à prática profissional da equipe do CRAS, além de conviver com o dilema da estrutura de trabalho, a equipe é convocada a trabalhar com base na perspectiva interdisciplinar. As famílias atendidas no CRAS apresentam situações de vulnerabilidades e riscos sociais que não são frutos de fatos homogêneos ou isolados, pelo contrário, são situações multifacetadas, por isso o trabalho interdisciplinar se torna tão importante na intervenção das demandas familiares.

Uma vez que as famílias apresentam tais situações, necessário se faz um olhar que não as fragmente, ou seja, que não faça um recorte da realidade social na qual a família está inserida, mas que vise intervir em tal realidade mediante olhar mais global, macrossocial, fato que muitas vezes apenas uma ciência/profissão não é capaz de dar conta. Várias profissões, no entanto, atuando juntas têm condições de realizar uma análise de conjuntura dessas demandas capaz de produzir intervenções mais eficazes.

Ressaltamos que a interdisciplinaridade não pressupõe uma uniformidade do pensar e não desconsidera as especificidades das diversas profissões, mas interdisciplinaridade requer que por meio de diálogo, contraposição das ideias, questionamentos e exposição dos diversos pontos de vistas se busque possibilidades de intervenções que sejam capazes de desenvolver uma visão social que tenha condições de, em meio a um contexto permeado por situações de privações, perceber as forças e não somente as fragilidades que as variadas circunstâncias de vida possuam. (BRASIL, 2004).

\section{Referências}

BRASIL. Política Nacional de Assistência Social. Brasília: Ministério do Desenvolvimento Social e Combate à Fome/ Secretaria Nacional de Assistência Social, 2004.

. SUAS: Sistema Único de Assistência Social. Brasília: Secretaria Nacional de Assistência Social, 2007.

CAMPOS, E. B. O protagonismo do usuário da Assistência Social na implementação e controle social do SUAS. In: Cadernos de textos: subsídios para debates: participação e controle social do SUAS. Brasília. Conselho Nacional de Assistência Social/Ministério do Desenvolvimento Social e Combate à Fome. 2009. p.17-24.

CFP/CFESS. Parâmetro para atuação de assistentes sociais e psicólogos (as) na Política de Assistência Social. Brasília: Conselho Federal de Psicologia (CFP), Conselho Federal de Serviço Social (CFESS), 2007.

COUTO, B. R. O direito social e a assistência social na Sociedade Brasileira: uma equação possível? 3. ed. São Paulo: Ed. Cortez, 2008.

CRESS - Conselho Regional de Serviço Social 11.Região. Lei Orgânica de Assistência Social. In: Legislação Social: cidadania, políticas públicas e exercício profissional. 2.ed. Curitiba: CRESS 11. Região, 2007.

FREIRE, P. Conscientização: teoria e prática da libertação: uma introdução ao pensamento de Paulo Freire. Tradução de Kátia de Mello e Silva. 3.ed. São Paulo: Ed. Moraes, 1980.

Ação cultural para a liberdade. 5. ed. Rio de Janeiro: Ed. Paz e Terra, 1981.

Pedagogia do oprimido. 48. reimp. Rio de Janeiro:

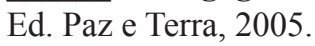

FREIRE, P.; SHOR, I. Medo e ousadia: o cotidiano do professor. Rio de Janeiro: Ed. Paz e Terra, 1986.

FREIRE, P.; MACEDO, D. Alfabetização: leitura do mundo, leitura da palavra. 4. ed. Rio de Janeiro: Ed. Paz e Terra, 2006.

GIL, A. C. Métodos e técnicas de pesquisa social. São Paulo, Ed. Atlas: 1994.

HOROCHOVSKI, R. R. Associativismo civil, democracia e empoderamento na colônia de pescadores de Matinhos no Paraná. 2007. 265 f. Tese de doutorado em Sociologia Política. Universidade Federal de Santa Catarina. Florianóplois, 2007. Disponível em: <www.tede.ufsc.br/teses/ PSOP0282.pdf $>$. Acesso em: 20 abril 2009.

IAMAMOTO, M. V. Serviço Social em tempo de capital fetiche: capital financeiro, trabalho e questão social. 4. ed. São Paulo: Ed. Cortez, 2010.

MÉSZAROS, I. A educação para além do capital. Tradução de Isa Tavares. São Paulo: Ed. Boitempo, 2005. 
MINAYO, M. C. S. (Org.). Pesquisa social: teoria, método e criatividade. Petrópolis: Editora Vozes, 1998.

MOROZ, M.; GIANFALDONI, M. H. T. A. O processo de pesquisa: iniciação. Brasília: Ed. Plano, 2002.

PEREIRA, P. A. P. Necessidades humanas: subsídios à crítica dos mínimos sociais. S. Paulo: Ed. Cortez. 2000.

RYZEWSKI, L. A.; STORTI, M. M. T. Pedagogia do oprimido e protagonismo juvenil: contribuições para uma práxis libertadora. Disponível em: <www.paulofreire.org/.../ ensaio_protagonismo_sob_a_inspiracao_de_Paulo_Freire. doc $>$. Acesso em: 10 fevereiro 2010.

SIMIONATO, I. Expressões ideoculturais da crise na atualidade e sua influência teórico-prática. In: SERVIÇO SOCIAL: direitos sociais e competências profissionais. Brasília: CFESS/ABEPSS, 2009. p. 87-102.

SOUZA, H. Participação. Disponível em: <http://www. tecsi.fea.usp.br/eventos/Contecsi2004/BrasilEmFoco/ port/polsoc/partic/apresent/apresent.htm>. Acesso em: 02 fevereiro 2010.

SPOSATI, A.; FALCÃO, M. C.; TEIXEIRA, S. M. F. Os direitos (dos desassistidos) sociais. 3. ed. São Paulo, Ed. Cortez, 1999.

YAZBEK, M. C. Classes subalternas e assistência social. 2. ed. São Paulo: Ed. Cortez. 1996.

Recebido em: 30 de agosto de 2012.

Aceito em: 03 de junho de 2013. 